\title{
Experimental study of the treatment measures for rail corrugation on tracks with Egg fasteners track in the Beijing metro
}

\author{
Weifeng Liu ${ }^{1}$, Hougui Zhang ${ }^{2}$, Weining Liu ${ }^{1}$, David J Thompson ${ }^{3}$ \\ ${ }^{1}$ School of Civil Engineering, Beijing Jiaotong University, Beijing 100044, China \\ ${ }^{2}$ Beijing Municipal Institute of Labour Protection, Beijing 100054, China \\ ${ }^{3}$ Institute of Sound and Vibration Research, University of Southampton, Highfield, Southampton SO17 1BJ, UK \\ Corresponding author \\ Weifeng Liu, School of Civil Engineering, Beijing Jiaotong University, No.3 Shangyuancun, Haidian District, Beijing 100044, \\ People's Republic of China. \\ Email: wfliu@bjtu.edu.cn
}

\begin{abstract}
Rail corrugation occurring on track fitted with Egg fasteners has become a serious problem on newly operated lines of the Beijing metro in recent years. Investigations and field measurements show that the dominant wavelengths of corrugation are 63-100 mm, inducing dominant frequencies of vibration on the rail in the frequency range $160-310 \mathrm{~Hz}$ for train speeds $60-70 \mathrm{~km} / \mathrm{h}$. Due to the influence of the track dynamic behaviour on the formation of rail corrugation, various options for changing the dynamic behaviour of the track structure can be considered as possible solutions to treat the corrugation. Four treatment measures have been considered: rail grinding, adding a rubber pad within the fastener, replacing the fastener with a compression-type fastener, and installing rail dampers on the rail. Field experiments have been carried out to evaluate the effectiveness of these rail corrugation treatments on two lines of the Beijing metro. Frequency response functions (FRFs), track decay rates, and pass-by acceleration on the rail were measured, and the development of rail roughness was monitored. Experimental results show that the four measures are all effective to control or at least slow the growth of rail corrugation on tracks with Egg fastener. Rail grinding is mostly used to limit the effects of corrugation; here, it was noted that low-amplitude corrugation on some straight lines did not reappear after rail grinding. After adding a rubber pad within the fastener, existing corrugation reduced in amplitude, while corrugation did not re-appear on newly ground rail. Replacing the fastener with a compression-type fastener and installing rail dampers on the rail were both found to slow the growth of corrugation.
\end{abstract}

\section{Keywords}

Metro, rail corrugation, Egg fastener track, treatment, field experiments 


\section{Introduction}

For more than a century, many studies have been carried out into the formation of rail corrugation. Some review papers ${ }^{1-5}$ indicate that corrugation occurs due to several different mechanisms, which could be combined in different ways, and consequently there is not a unique general procedure for its treatment. Grassie and Kalousek proposed a classification of rail corrugation in their papers ${ }^{4,5}$. Six different types of corrugation with significant different characteristics were identified, and treatment measures for each type were also recommended. Some solutions have also been proposed to reduce the corrugation growth in past studies. Rail grinding is the most frequently recommended treatment, but generally this is not considered as a solution, but as a way of limiting the negative effects of corrugation. Other treatments include modifying the friction coefficient $^{6,7}$, increasing the hardness of the rail ${ }^{8}$, reducing the stiffness of the rail pad $^{9,10}$ and changing operational modes of the trains ${ }^{11}$.

Rail corrugation has become a serious problem on several newly operated lines of the Beijing metro in recent years. This problem is becoming a great concern because the intense noise and vibration due to rail corrugation lead to complaints from the residents living near metro lines, as well as passengers and staff in the trains. Moreover, increasing failures of the clips in the fastening system and cracks of the bogie frame of the train have been found in severely corrugated sections, while this did not occur on smooth tracks $^{12}$. The large amount of maintenance work resulting from corrugation has also become a significant problem in the Beijing metro.

Field measurements have been conducted in the Beijing metro to investigate the cause of the rail corrugation and to study solutions to treat it. Based on these investigations, the most severe corrugation was found on rails where Egg fasteners are used. This fastening system has a low vertical stiffness which is intended to minimize vibration transmitted into the ground. It is used in a large range of situations, from tight curves to straight lines and is found to be prone to corrugation in each situation. A typical corrugated rail is shown in Figure 1.

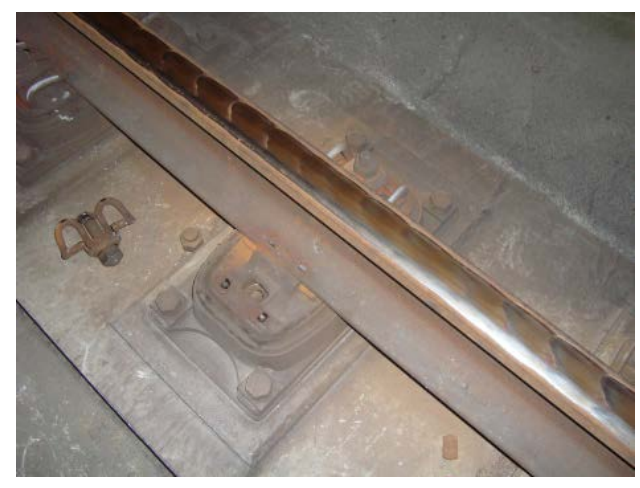

Figure 1. Corrugation exhibited on the rail with Egg fastener. Note the broken rail fastener

A recent study into the mechanism of corrugation on the Egg fastener track in the Beijing metro identified the dominant frequencies of the corrugation ${ }^{12}$. The rail roughness on the running band of the corrugated rails was measured in sections of track with Egg fasteners by means of a corrugation analysis trolley $(\mathrm{CAT})^{13}$. The dynamic response of the track was 
also measured, including the FRFs, track decay rates, and pass-by acceleration on the track. According to the roughness measurements, the dominant wavelength band for the corrugation on the rail with Egg fasteners is 63-100 mm, which induces dominant frequencies of vibration on the rail in the range $160-310 \mathrm{~Hz}$ for train speeds of 60-70 km/h.

According to the categories suggested by Grassie $^{5}$, the corrugation on the rail with Egg fasteners appears to be attributable to the “trackform-specific” type. This normally requires a pronounced resonance of the track. In the case of the Egg fasteners in the Beijing metro ${ }^{12}$, a series of lightly damped resonances are found between 160 and $310 \mathrm{~Hz}$, as will be discussed further here.

Based on the results of these investigations and measurements, various solutions intended to reduce the development of rail corrugation have been proposed. One possibility is to change the dynamic behaviour of the track structure to remove the resonance peaks, or to enhance the damping of the track. To achieve this, the addition of a rubber pad within the Egg fastener or the replacement of the fastener by a compression-type fastener have been considered. To increase the damping, a tuned rail damper has been installed. Field experiments have been carried out on Line 10 and Line Yizhuang of the Beijing metro to evaluate the effectiveness of these measures in suppressing the corrugation growth. In addition the effect of rail grinding has been assessed. These experiments and their results are described in this paper.

\section{Description of rail corrugation on Egg fastener track in the Beijing metro}

The Beijing metro is a rapid transit system that serves Beijing city and its various suburbs. 19 lines (about $600 \mathrm{~km}$ ) are currently in operation, and 9 further lines are under construction, which will result in a network of 28 lines (about 1000 $\mathrm{km})$ by 2020. To reduce the environmental vibration induced by the passage of metro trains, a variety of track forms are in use in the Beijing metro, including the Egg fastener track, ladder track, and floating slab track. However, rail corrugation has become a serious problem in several newly operated lines since 2007, especially on track fitted with the Egg fastener system.

The Egg fastener (shown in Figure 2) has a very low static stiffness of $8-12 \mathrm{kN} / \mathrm{mm}$, which is used to mitigate the environmental vibration induced by moving trains. The stiffness of the Egg fastener is provided by the shear deformation of an oval rubber ring. The rubber ring is vulcanized onto an upper steel plate attached to the rail and a side steel plate connected to the track slab. In addition, a stiff pad (not shown) is inserted between the upper plate and the rail foot.

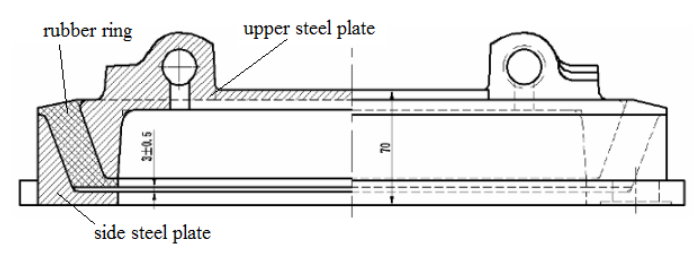

Figure 2. Egg fastener 
Measurements have been made to quantify the extent of corrugation and its association with different fastening systems. According to these measurements, a large amount of corrugation occurs in the sections of track fitted with Egg fasteners. For example, on Line 4 there is 12.73 $\mathrm{km}$ of Egg fastener track where the train speed is $60-70 \mathrm{~km} / \mathrm{h}$, of which $7.13 \mathrm{~km}$ was found to be corrugated. Similarly, on Line 5 there is $12.28 \mathrm{~km}$ of such track of which $5.01 \mathrm{~km}$ was corrugated. Of the total length of corrugated track on Line 4, about 61\% occurred on Egg fastener track; this percentage was $80 \%$ on Line 5 although this track form represented $38 \%$ of the track on this line. For Egg fastener track on Line 5, the likelihood of corrugation increased from $16 \%$ on tangent track to $75 \%$ for radii less than $400 \mathrm{~m}$. The likelihood was $41 \%$ where the line speed is $60 \mathrm{~km} / \mathrm{h}$ and above; it was only $2 \%$ where the speed is less than $60 \mathrm{~km} / \mathrm{h}^{12}$

In order to determine the corrugation wavelengths on Egg fastener track, a CAT was used to measure the running band roughness of corrugated rail. The rail roughness wavelength spectra of three typical Egg fastener sections with different curve radii are shown in Figure 3. The dominant wavelengths of corrugation are in the 63 $\mathrm{mm}, 80 \mathrm{~mm}$ and $100 \mathrm{~mm}$ bands. The corrugation on Egg fastener track appeared in the track sections where the speed of trains is $60-70 \mathrm{~km} / \mathrm{h}$. The relation between the corrugation wavelength and the train speed $f=V / \lambda$ gives the dominant frequencies excited by the corrugation as occurring in the range 160-310 Hz.

\section{Wheel/track dynamic behaviour}

\section{Track dynamics}

In this section the dynamic behaviour of the track and wheel are investigated, with particular emphasis on the frequency region $160-310 \mathrm{~Hz}$.

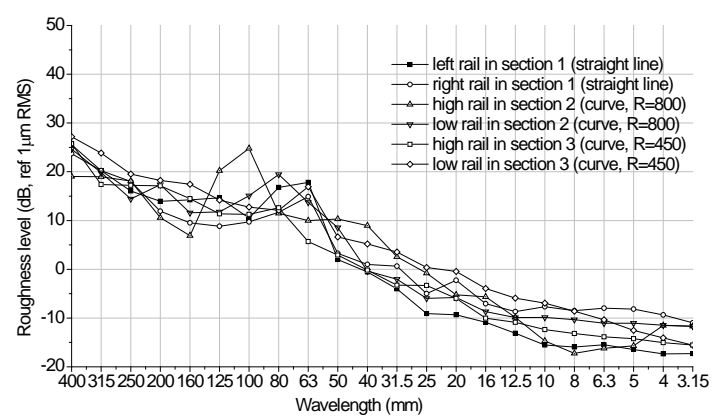

Figure 3. Corrugation wavelength spectrum of three typical Egg fastener sections with different curve radii

The dynamic behaviour of the Egg fastener track structure was measured on unloaded tracks in the Beijing metro by applying impact excitation to the rail using an instrumented hammer. The results were obtained in the form of the FRFs (acceleration/force) and the decay rate of the track. The acceleration of the rail during a train pass-by was also measured.

Typical FRFs obtained are shown in Figure 4. At about $1000 \mathrm{~Hz}$, a peak is found in the FRF between fasteners and a corresponding dip above a fastener; this is the vertical 'pinned-pinned resonance'. As the dominant frequencies of corrugation are found in the range $160-310 \mathrm{~Hz}$, this indicates that the 'pinned-pinned resonance' is not the cause of the rail corrugation in this case. 
On the other hand, strong peaks are found in the FRF at the frequencies of $160 \mathrm{~Hz}, 180 \mathrm{~Hz}, 210 \mathrm{~Hz}$, $280 \mathrm{~Hz}$ and $310 \mathrm{~Hz}$, which coincide with the dominant frequency range 160-310 Hz.

Furthermore, the FRF was also measured on a $0.4 \mathrm{~m}$ length of rail supported by an Egg fastener in the laboratory to obtain the dynamic behaviour of the Egg fastener itself (Figure 5). Figure 6 shows the vertical FRF measured in the laboratory. The peaks in the range $160-310 \mathrm{~Hz}$ can still be seen at the same frequencies as in
Figure 4, which indicates that these peaks occur due to the dynamic behaviour of Egg fastener itself.

Figure 7 shows the frequency content of typical vertical acceleration in an Egg fastener section without corrugation during the passage of a train. This was measured in a curve with $800 \mathrm{~m}$ radius for a train speed $80-90 \mathrm{~km} / \mathrm{h}$. There is a strong dynamic response in the frequency range 150 to $400 \mathrm{~Hz}$.

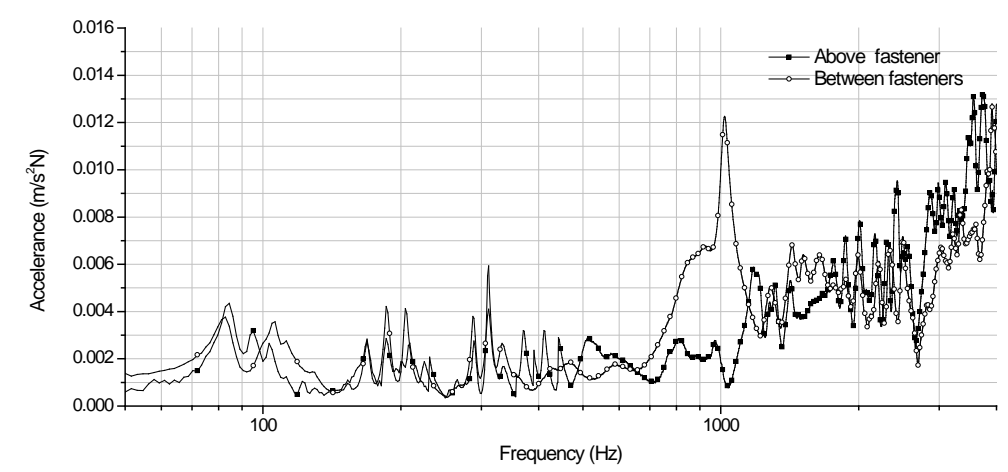

Figure 4. Measured vertical FRFs of rail with Egg fastener in the Beijing metro (fastener spacing 625 $\mathrm{mm})$

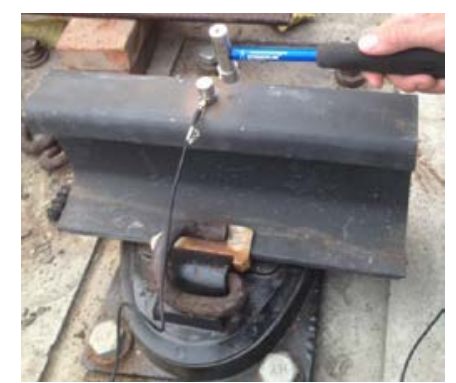

Figure 5. Measurement of FRF on a rail with Egg fastener in the laboratory 


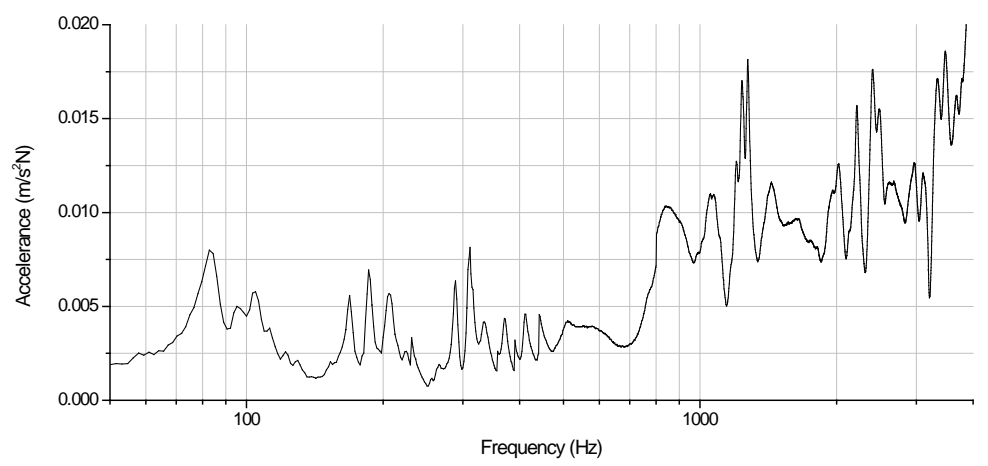

Figure 6. Measured vertical FRF of rail with Egg fastener in the laboratory

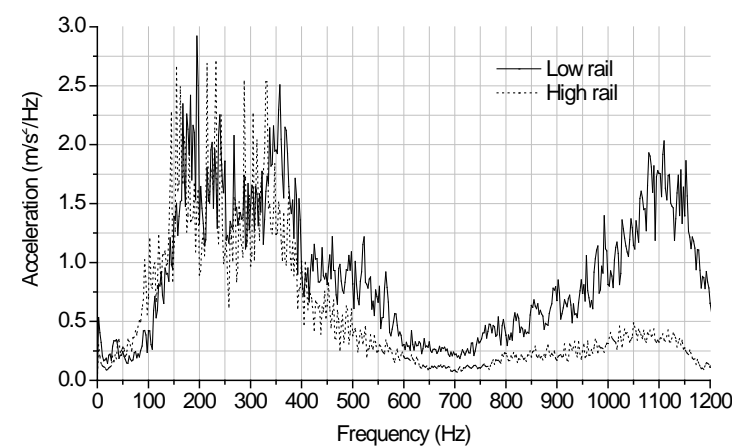

Figure 7. Measured vertical acceleration on the rail in Egg fastener section without corrugation during train passage

\section{Wheelset dynamics}

To determine the dynamic behaviour of the wheelset, a finite element model was set up (Figure 8). In this model, the wheelset is attached to a rigid bogie through springs and dashpots representing the primary suspension in the vertical and lateral directions. The wheel diameter is $840 \mathrm{~mm}$. The corresponding rigid-body modes have natural frequencies below $10 \mathrm{~Hz}$. The vertical receptance of both the driven wheelset and the non-driven wheelset was calculated.

Figure 9 and Figure 10 show the vertical receptance of the driven wheelset and the non-driven wheelset, respectively. There is a strong dip in the region of $300 \mathrm{~Hz}$ in both cases. Below this frequency the receptance is predominantly mass-controlled and above this frequency it is predominantly stiffness-controlled. Strong resonances at around $100 \mathrm{~Hz}$ and $475 \mathrm{~Hz}$ are associated with the axle bending.

At this anti-resonance the wheel/rail contact forces can be expected to reach a maximum. However, analysis if the wheel/track interaction is beyond the scope of this paper.

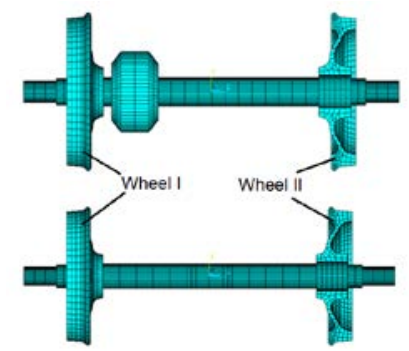

Figure 8. Finite element model of wheelset used in the Beijing metro and its cross-sectional element detail of wheel 


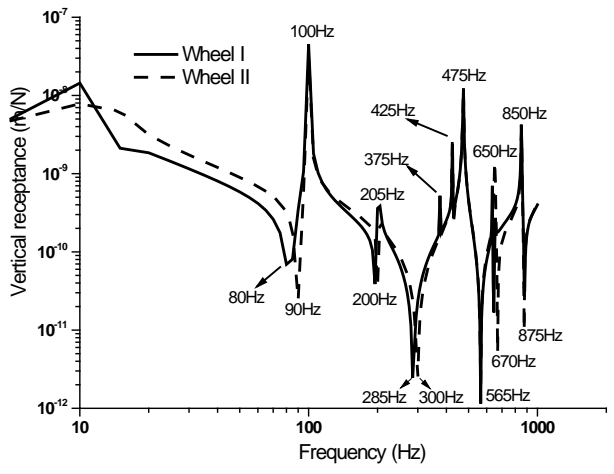

Figure 9. Vertical receptance of the two wheels of the driven wheelset

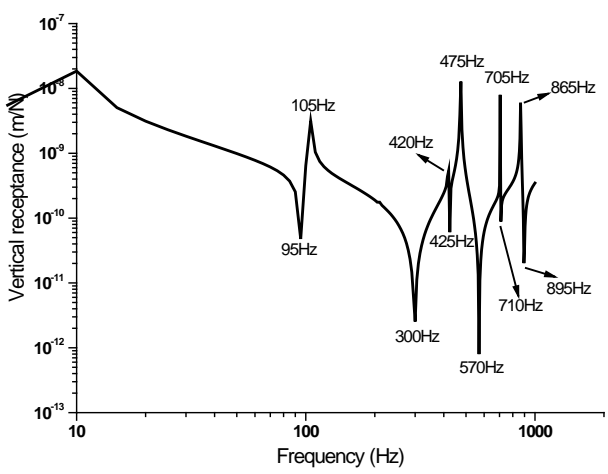

Figure 10. Vertical receptance of non-driven wheelset (identical at both wheels)

From these numerical calculations and measurements it has been confirmed that the large vibration of the track in the frequency region $160-310 \mathrm{~Hz}$ is associated with the dynamic (a) behaviour of the track structure as well as the anti-resonance of the wheelset. Various solutions will therefore be investigated which modify the dynamic behaviour of the track structure in this frequency range.

\section{Track decay rates}

In addition, the track decay rate of the Egg fastener track was also measured according to the standard EN 15461: 2008+A1: $2010^{14}$. Apart from the assessment of rolling noise from the track ${ }^{14,15}$, the track decay rate can be used to evaluate its damping $^{16,17}$. Figure 11 shows typical vertical and transverse track decay rates of Egg fastener track measured in the Beijing metro. The track decay rate is very low (less than $0.4 \mathrm{~dB} / \mathrm{m}$ ) for both the vertical and transverse directions in the frequency range 200-315 Hz. This indicates that the damping of the track is particularly low in this frequency range. Thus, enhancing the damping of the Egg fastener track could also have a beneficial effect on the corrugation growth rate. 

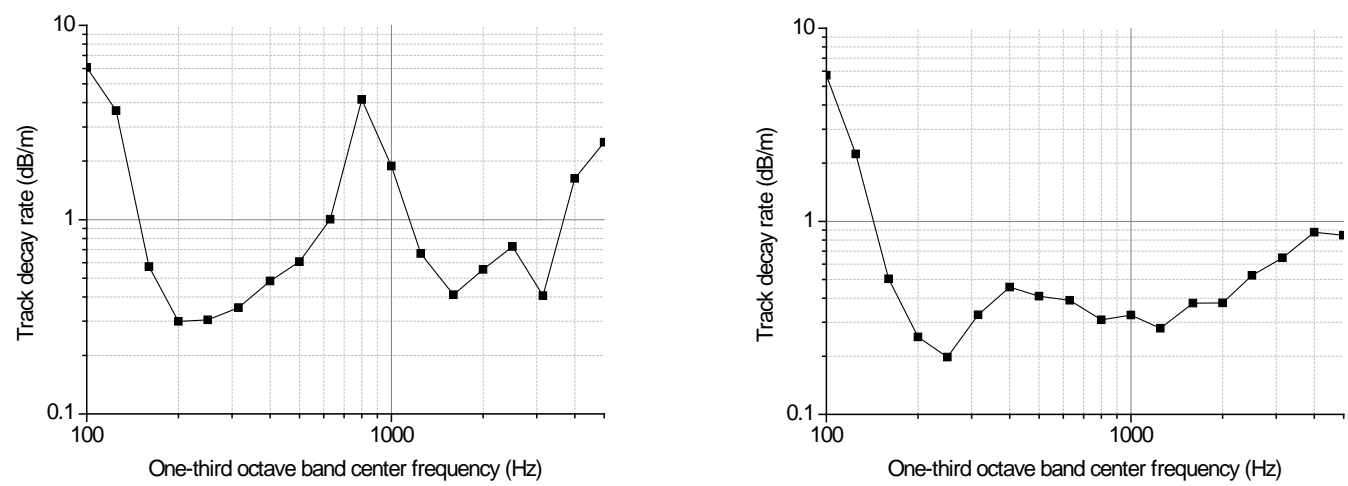

Figure 11. (a) Vertical and (b) transverse track decay rates of Egg fastener track

\section{Treatment of rail corrugation}

\section{Rail grinding}

Amongst the solutions to suppress or reduce the rail corrugation growth, rail grinding is frequently used in most situations. Generally, rail grinding is not considered as a permanently effective solution. Nevertheless, this is one of the treatment measures considered in the present study. After rail grinding, it was found that the corrugation did not reoccur for $23 \%$ of the total length of corrugated rail fitted with Egg fasteners on Lines 5 and 10. Because grinding was not carried out on the new rail before the new lines were brought into operation, it appears that this was sufficient to prevent the corrugation from reoccurring after the original roughness-induced corrugation was removed. However, it should be noted that it was only small amplitude corrugation on some straight lines that did not reoccur after the rail grinding, whereas the more serious corrugation on other straight sections and particularly on curves still grew rapidly after the rail grinding. Due to this rapid growth, the shortest time interval between successive grinding was less than three months on Line 4.

\section{Rubber pad in Egg fastener}

There is a hollow space inside the Egg fastener (Figure 2), so it is possible to insert a rubber pad into this space to change the stiffness of the fastener. A rubber pad (Figure 12) has been designed to be installed between the upper steel plate and the sleeper surface and fit fully within this space in the fastener. The original rubber ring is retained, so the stiffness of the modified fastener is provided partly by shear deformation of the rubber ring and partly by compressional deformation of rubber pad. The total static stiffness of the modified fastener becomes 18 $\mathrm{kN} / \mathrm{mm}$.

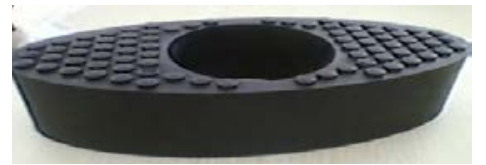

Figure 12. Rubber pad inserted in Egg fastener

To evaluate the effectiveness of this 
approach in treating the corrugation, an experiment was performed on Line 10 of the Beijing metro. The rubber pad was fitted in two experimental sections which had serious rail corrugation. Section 1 is a straight line (50 m long, train speed $V=60-70 \mathrm{~km} / \mathrm{h}$ ), and section 2 is in a curve (80 m long, radius $R=450 \mathrm{~m}, V=60-70$ $\mathrm{km} / \mathrm{h})$. The rail in section 1 was ground before the experiment, while it was not for section 2.

To assess the influence of the rubber pad on the dynamic behaviour of the track structure, the FRFs were measured after its installation in section 1. Figure 13 shows the FRFs of the Egg fastener track with the rubber pad, compared with the earlier measurements without the pad at a different location (Figure 4). From this it appears that adding the rubber pad within the Egg fastener causes the peaks to move to higher frequencies.

After the installation of the rubber pads within the Egg fastener, four measurements of running band roughness in the two experimental sections were carried out over a period of about half a year. Figure 14 shows comparisons of the $500 \mathrm{~mm}$ moving average peak-to-peak roughness amplitude (PPR) filtered in the 30-100 mm wavelength range from the first and the last measurements. Figure 15 shows the roughness spectra in the two sections at different times after installation. Superimposed on Figure 15 is roughness level limit line taken from the ISO 3095: 2013 standard $^{18}$, which corresponds to a "smooth" rail. The roughness level is lower than the ISO 3095 limit at most wavelengths for section 1 after the rail grinding. However, it exceeds the limit at all wavelengths for section 2, which had not been ground, especially at $63 \mathrm{~mm}$ wavelength, which indicates the serious corrugation in section 2. Figure 16 shows the development of the roughness level at the dominant wavelength in the two sections.

For section 1, the moving average PPR in Figure 14(a) shows only a small change, and the roughness level at the dominant wavelength in Figure 16 is nearly unchanged, which indicates the corrugation did not grow after the rail grinding. For section 2, which had not been ground, the roughness dropped significantly after installation of the rubber pads. The roughness level at the dominant wavelength was on average $6.3 \mathrm{~dB}$ lower after six months. Because adding the rubber pad changes the dynamic behaviour of the Egg fastener, the original corrugation at the dominant wavelength was worn down by the rolling wheels, causing the roughness level to reduce. Moreover, no new dominant wavelength appeared according to Figure 15. So adding the rubber pad in the Egg fastener is effective in reducing the corrugation. However, this results in a decrease in the vibration mitigation due to the increase of the fastener stiffness. Therefore, the rubber pad can only be adopted in the Egg fastener in track sections where the requirement for reducing the environmental vibration is less critical. 


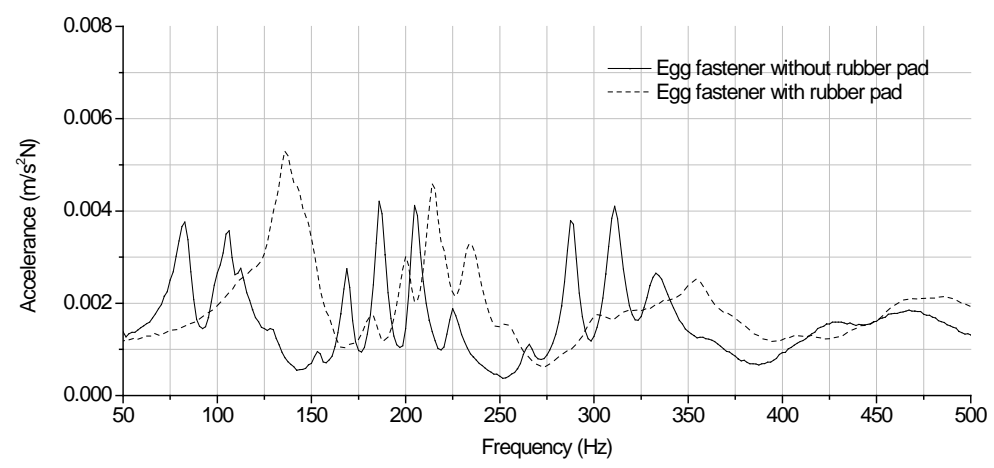

Figure 13. Measured vertical FRFs (with and without rubber pad in Egg fastener)

(a)

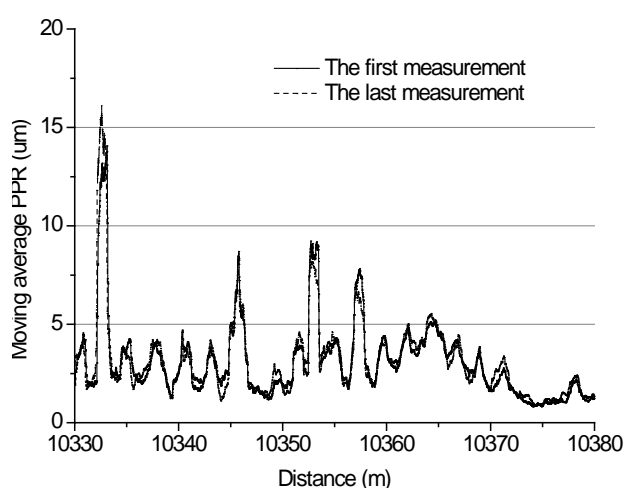

(b)

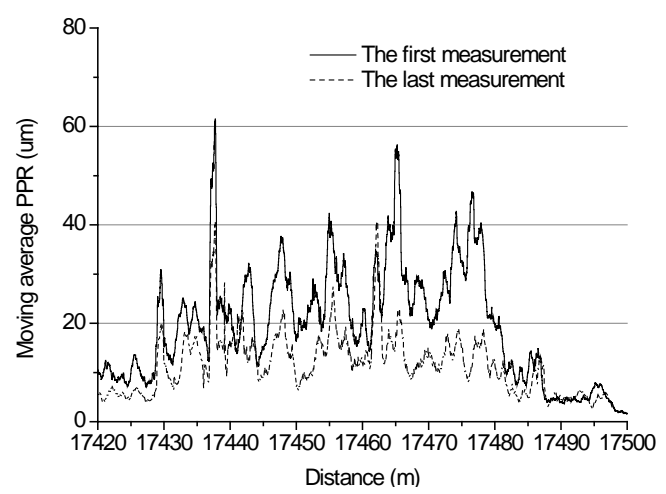

Figure 14. Moving average PPR in 30-100 mm wavelength band for the first and the last measurements after fitting rubber pad in Egg fastener in (a) section 1 and (b) section 2

(a)

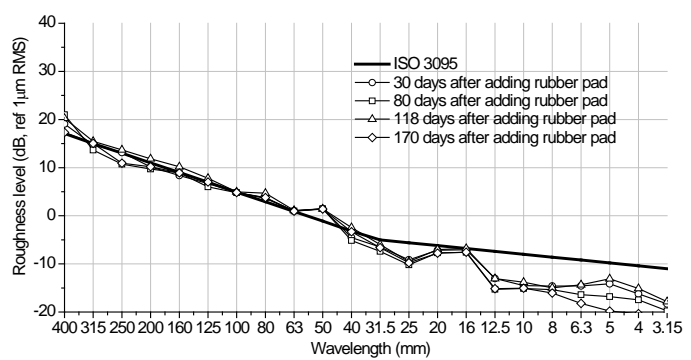

(b)

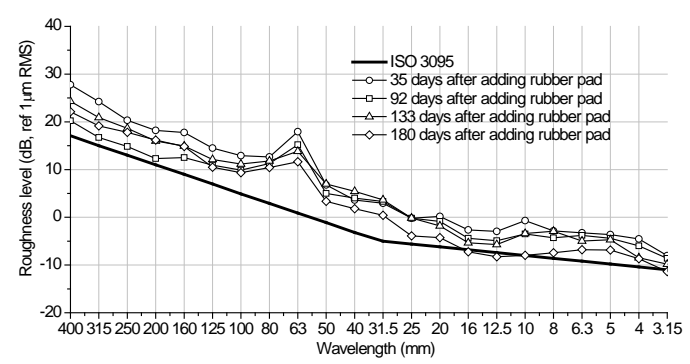

Figure 15. Development of roughness level in (a) section 1 and (b) section 2 


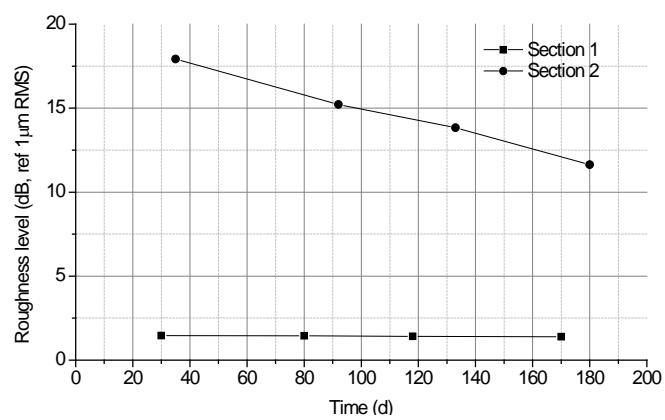

Figure 16. Development of roughness level at the dominant wavelength after fitting rubber pad in Egg fastener

\section{Compression-type fastener}

To change the dynamic behaviour of the Egg fastener track structure, an alternative fastening system can also be proposed. A compression-type fastener was chosen (Figure 17) with a similar static stiffness of $8-14 \mathrm{kN} / \mathrm{mm}$ so that the vibration mitigation effect can be maintained. The stiffness of this fastener is provided by compression of a rubber pad between upper and lower steel plates.

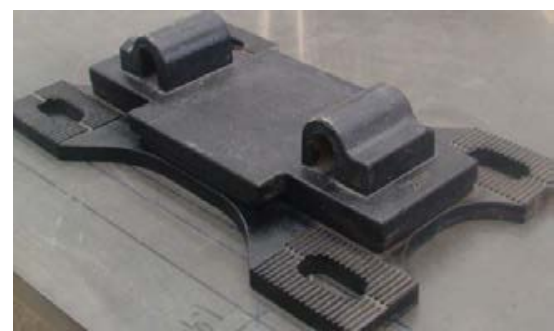

Figure 17. Compression-type fastener

An experiment was carried out on Line 10 of the Beijing metro to assess the effectiveness of this fastener system in treating corrugation. A 140 $\mathrm{m}$ experimental section was selected, which consists of a $55 \mathrm{~m}$ reference section (Egg fastener) and an $85 \mathrm{~m}$ replacement section fitted with the compression-type fastener. The experimental section is in a curved tunnel with a radius of 500 $\mathrm{m}$; the train speed is $60 \mathrm{~km} / \mathrm{h}$.

The FRF was measured after the installation of the compression-type fastener in the replacement section, and nine measurements of the rail roughness in the running band of this experimental section were carried out over a period of 14 months to assess the corrugation growth.

Figure 18 shows the measured FRFs of the track with compression-type fasteners compared with the previous measurement of the Egg fastener track. The peaks between 160 and $310 \mathrm{~Hz}$ seen previously for the Egg fastener track do not appear for the compression-type fastener.

Figure 19 shows the rail roughness in the form of the $500 \mathrm{~mm}$ moving average PPR in the 30-100 $\mathrm{mm}$ wavelength range for the first measurement (70 days after replacement) and the last one (405 days after replacement). For most of the Egg fastener section, in Figure 19(a), the moving average PPR increases, while it tends to 
reduce slightly for the compression-type fastener in Figure 19(b). Figure 20 shows the roughness spectra in the two track sections for three measurements. The roughness levels greatly exceed the ISO 3095 limit, indicating that the corrugation is very severe in both sections. The development of the roughness level at the dominant wavelength of $80 \mathrm{~mm}$ is shown in Figure 21. The roughness level at the dominant wavelength increases for the Egg fastener track, while for the compression-type fastener it is fairly stable, reducing slightly after 158 days after the installation despite growing initially. These experimental results indicate that the compression-type fastener can be used to control the corrugation growth to some degree. However, a more reliable estimate of their effect would be obtained if the roughness could be monitored after rail grinding.

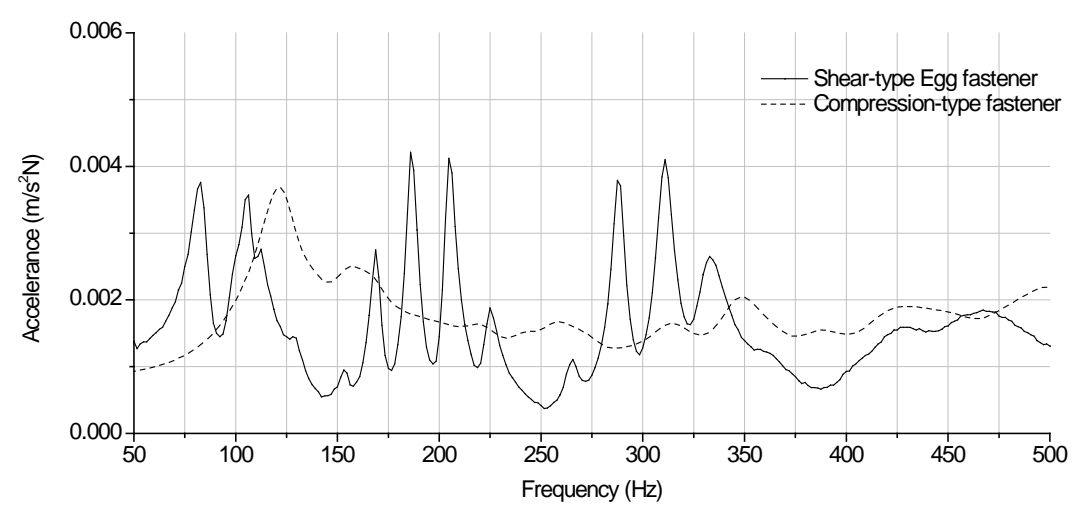

Figure 18. FRFs of Egg fastener track and compression-type fastener track

(a)

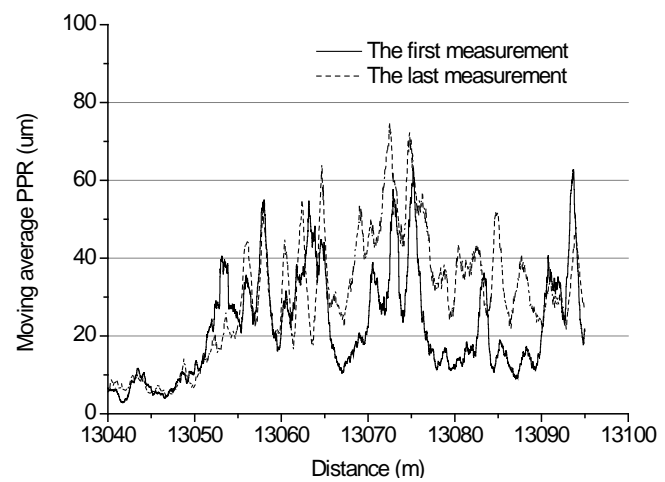

(b)

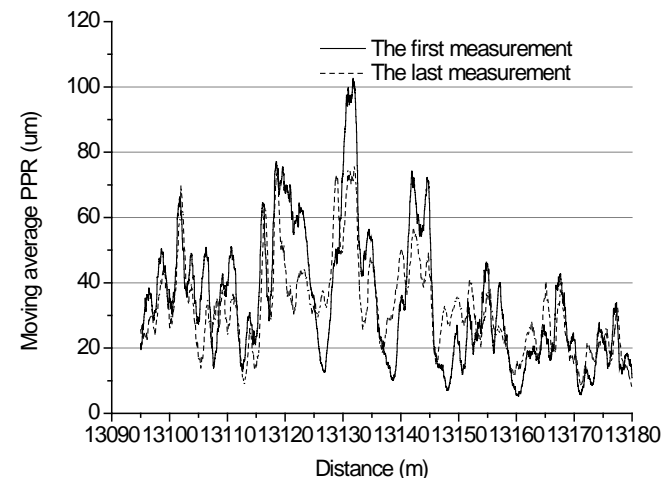

Figure 19. Moving average PPR in 30-100 mm wavelength band in (a) Egg fastener section and (b) compression-type fastener section 
(a)

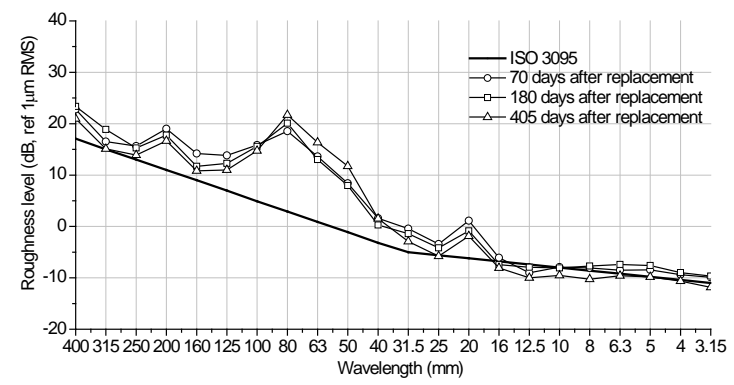

(b)

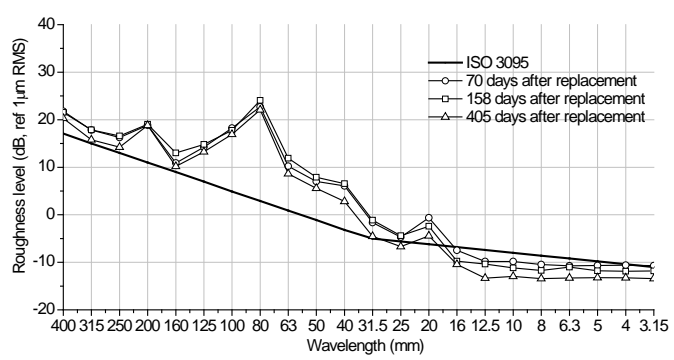

Figure 20. Development of roughness level in (a) Egg fastener section and (b) compression-type fastener section

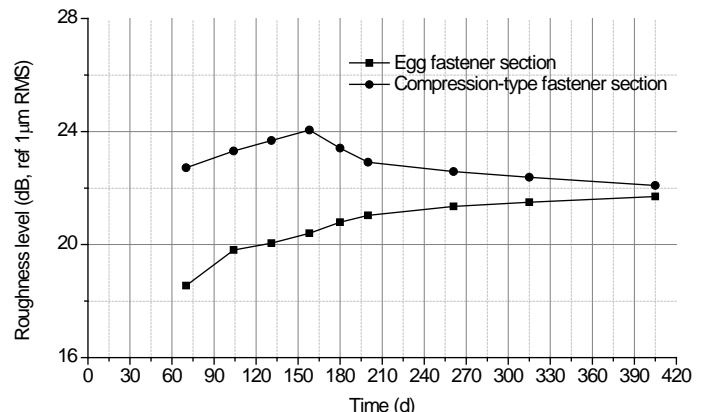

Figure 21. Development of roughness level at the dominant wavelength of $80 \mathrm{~mm}$

\section{Tuned rail damper}

As a means of enhancing the damping to suppress the vibration of the rail, a tuned rail damper was chosen for application in the Beijing metro. The rail damper consists of 2 or 3 steel mass blocks enclosed in an elastomeric material with a high damping loss factor, which is attached to each side of rail web by clips (Figure 22). It is a "mass-spring" system with a high damping loss factor which is therefore effective over a wide frequency range ${ }^{19,20}$. The rail damping device is mainly used to reduce wheel/rail rolling noise ${ }^{19,21-23}$. In addition, such rail damping devices have previously been proposed to reduce the corrugation growth at the wavelength corresponding to the frequency of the 'pinned-pinned resonance' (around $1000 \mathrm{~Hz})^{24-27}$. Although the dominant frequencies of 160-310 $\mathrm{Hz}$ excited by the corrugation on Egg fastener track in the Beijing metro are far away from the frequency of 'pinned-pinned resonance', the rail damper can be considered as a possible solution to increase the damping and reduce the vibration of the rail, which could contribute to suppression of the corrugation growth. 

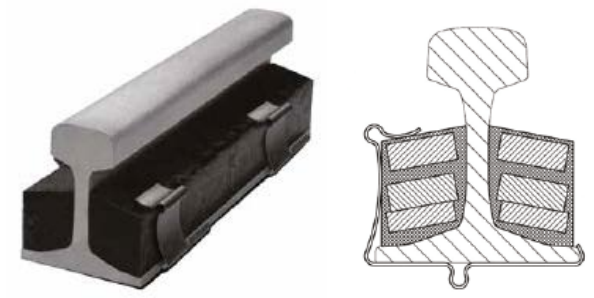

Figure 22. Tuned rail damper and its cross section $^{28}$

To study the effectiveness of the rail damper in suppressing the vibration of the rail and slowing the corrugation growth, an experiment was performed on Line Yizhuang of Beijing metro. An experimental section $200 \mathrm{~m}$ long was selected in a curve $(R=600 \mathrm{~m}, V=70 \mathrm{~km} / \mathrm{h}$, Egg fastener track) where the rail corrugation had been found to develop rapidly in the previous five years. The $200 \mathrm{~m}$ experimental section consists of one $100 \mathrm{~m}$ section with rail dampers fitted to the track (damper section) and another $100 \mathrm{~m}$ section without rail dampers (reference section). The two sections have the same track and operating conditions, which ensure an effective comparison of corrugation growth between them.

The track decay rate and the pass-by acceleration on the rail were measured before and after installation of the rail dampers in the damper section. The FRF of the track was also measured in the damper section.

The track decay rate was measured five days before and after rail damper installation in the damper section. Both the vertical and transverse decay rates were measured. These are shown in Figure 23. From this figure, it can be seen that, similar to Figure 11, the track decay rates were very low before rail damper installation, especially in the 200-500 $\mathrm{Hz}$ range. However, there is a large increase in track decay rates in this frequency range after installation of the rail damper. The vertical track decay rate after rail damper installation is 7-9 times that before its installation in this frequency range and is increased over the whole frequency range.

Figure 24 shows the FRFs of the Egg fastener track with and without rail dampers. A tendency can be observed that the peaks in the frequency range of $50-350 \mathrm{~Hz}$ for the track with rail damper move towards low frequency, and the amplitude of these peaks becomes much lower than that for the track without the rail damper.

In order to analyse the change of rail vibration due to the installation of the rail damper, the pass-by acceleration on both low and high rails was measured two days before and after its installation in the damper section while the rail was still corrugated. Figure 25 shows the frequency content of vertical pass-by acceleration on each rail. The acceleration after installation of the rail dampers is less than that before their installation at most frequencies. On the low rail there are sharp peaks in the vibration spectrum excited by rail corrugation at about $210 \mathrm{~Hz}$ and $300 \mathrm{~Hz}$ before rail damper installation. The corresponding peaks on the high rail have smaller amplitude. Although these peaks still appear after installation of the rail dampers, their amplitude is significantly reduced. Figure 26 shows the vertical acceleration levels on the two rails in one-third octave bands. After rail damper installation the acceleration level on the low rail reduces by $8-18 \mathrm{~dB}$ in the region $160-315 \mathrm{~Hz}$. The 
corresponding reduction for the high rail is $5-8 \mathrm{~dB}$. These results indicate that the rail damper can

(a)

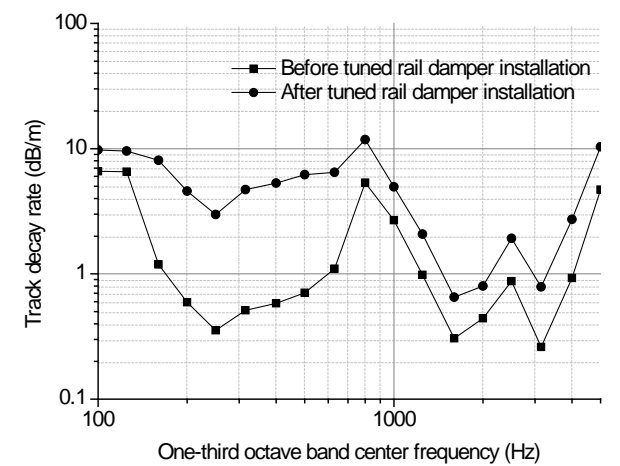

greatly reduce the pass-by rail vibration which is consistent with the increased track decay rate.

(b)

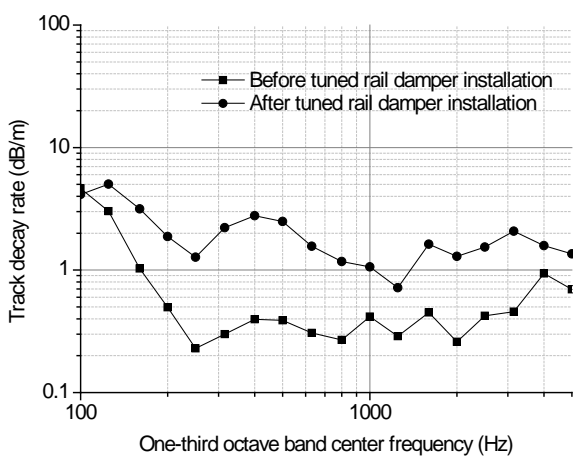

Figure 23. (a) Vertical and (b) transverse track decay rates before and after rail damper installation

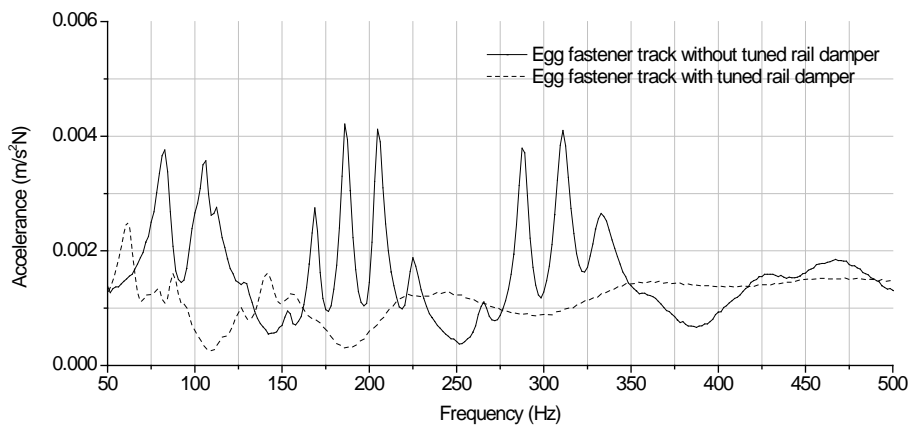

Figure 24. FRFs of Egg fastener track with and without rail damper

(a)

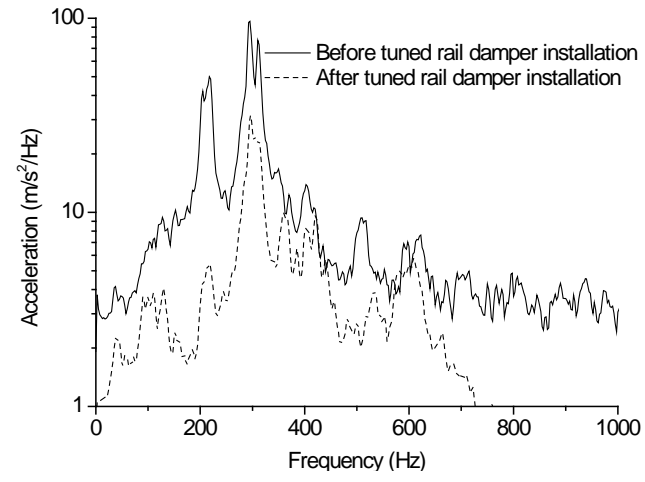

(b)

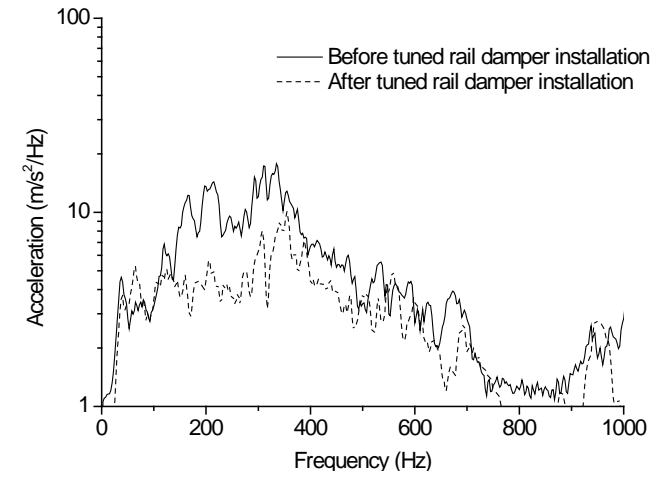

Figure 25. Frequency spectrum of vertical pass-by acceleration before and after installation of rail dampers, measured on (a) low and (b) high rail 
(a)

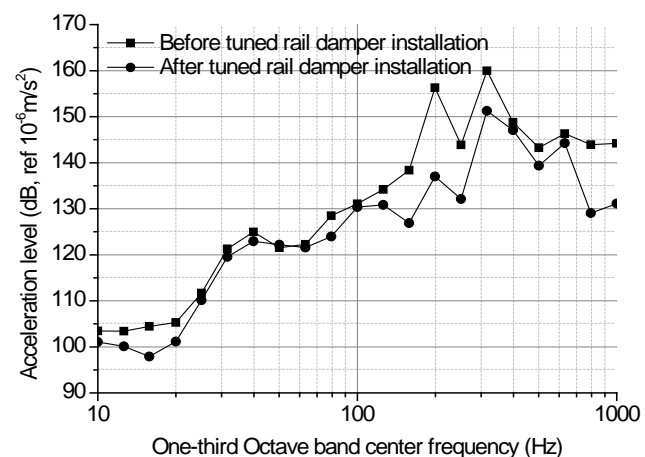

(b)

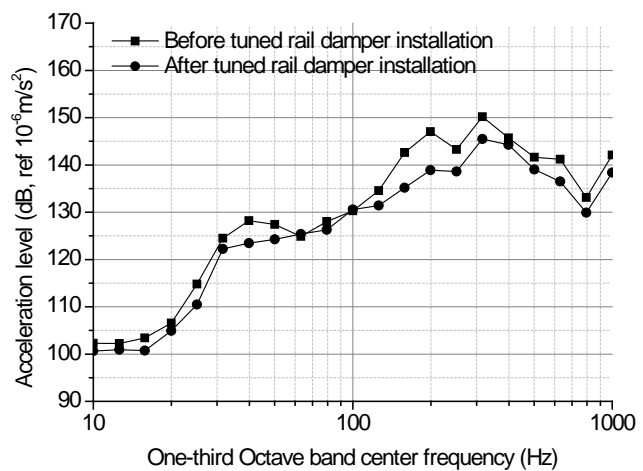

Figure 26. Vertical acceleration level before and after installation of rail dampers, measured on (a) low and (b) high rail in one-third octave bands

In order to assess the growth of corrugation, the running band roughness of the corrugated rail in the damper section and the reference section was measured by means of a CAT. Nine measurements of roughness were conducted, once every two months, to assess the corrugation development over a period of about 15 months. In addition the rail was ground during this period. Table 1 shows the dates of measurements, installation of rail dampers and rail grinding.

The 30-100 mm wavelength filtered moving average PPR from the first and the last measurements after rail grinding is shown in Figure 27. The roughness grows significantly in the reference section, while it has a relatively small growth in the damper section.
Table 1 Measurement dates of rail roughness in damper and reference sections

\begin{tabular}{|c|c|c|}
\hline Date & $\begin{array}{l}\text { Days before/after } \\
\text { rail grinding }\end{array}$ & Items \\
\hline 16 July 2013 & 121 (before) & CAT measurements \\
\hline 15-16 August 2013 & 90-91 (before) & $\begin{array}{l}\text { Installation of rail } \\
\text { dampers in damper } \\
\text { section }\end{array}$ \\
\hline 2 September 2013 & 72 (before) & CAT measurements \\
\hline 25 October 2013 & 19 (before) & CAT measurements \\
\hline 14 November 2013 & / & $\begin{array}{l}\text { Rail grinding in } \\
\text { damper and reference } \\
\text { sections }\end{array}$ \\
\hline 2 December 2013 & 19 (after) & CAT measurements \\
\hline 28 February 2014 & 107 (after) & CAT measurements \\
\hline 21 April 2014 & 159 (after) & CAT measurements \\
\hline 31 July 2014 & 260 (after) & CAT measurements \\
\hline 14 August 2014 & 304 (after) & CAT measurements \\
\hline 29 October 2014 & 380 (after) & CAT measurements \\
\hline
\end{tabular}

Figure 28 shows the roughness spectra in the reference section and the damper section. This 
indicates that the dominant wavelength of corrugation in both sections is $63 \mathrm{~mm}$. The roughness levels in the two sections exceed the ISO 3095 limit by $13-18 \mathrm{~dB}$ in the first three measurements. The rail corrugation was so serious that rail grinding was required, so the rails were ground after the third measurement. The rail grinding did not change the dominant wavelength, which remains $63 \mathrm{~mm}$, although the roughness level at this wavelength was reduced by around $20 \mathrm{~dB}$.

Figure 29 shows the development of roughness level in $63 \mathrm{~mm}$ wavelength band. The roughness increases significantly both before and after rail grinding for the reference section, while it increases more slowly for the damper section. The roughness level has a $12.5 \mathrm{~dB}$ increase between the first and the last measurements after rail grinding for the reference section (a period of 380 days), while this value is just $5.5 \mathrm{~dB}$ for the damper section. This indicates that the rail damper can slow the development of rail corrugation to less than half the original growth rate.

Consequently, the rail damper can also delay the need for rail grinding. Considering, for example, a roughness level in the $63 \mathrm{~mm}$ wavelength band of $6.9 \mathrm{~dB}$ as a notional level requiring grinding, in Figure 30, the roughness level for the damper section exceeds the level at the 765th day after grinding with the rail damper installed, while it is reached on the 330th day for the reference section. It should be noted that it is assumed that the roughness growth continues at the same rate after the monitoring. Therefore, according to this experiment, the frequency of rail grinding can be reduced by installation of the rail dampers to less than half its original value.

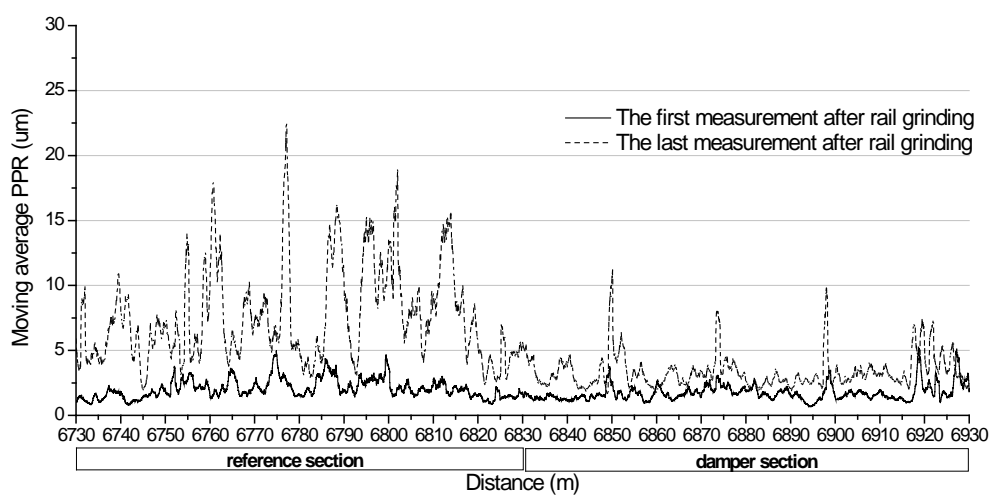

Figure 27. Moving average PPR in 30-100 mm wavelength band measured after rail grinding in reference section and damper section 
(a)

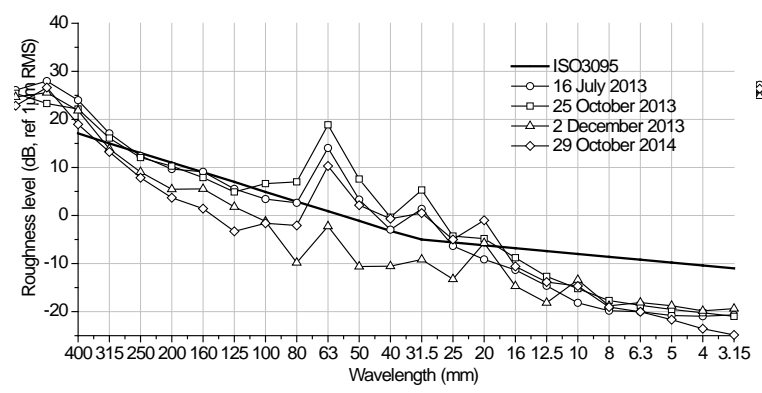

(b)

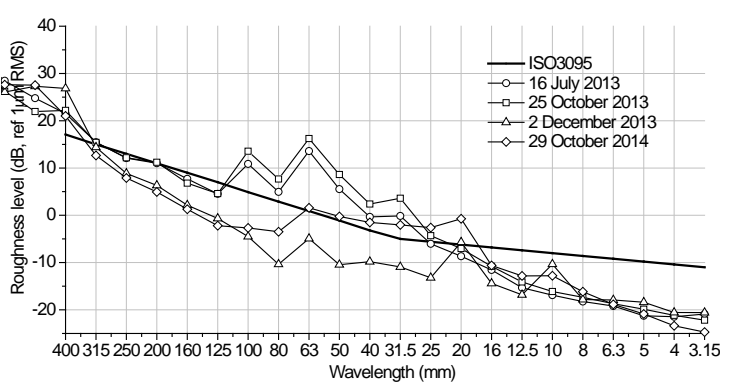

Figure 28. Roughness levels in (a) reference section and (b) damper section

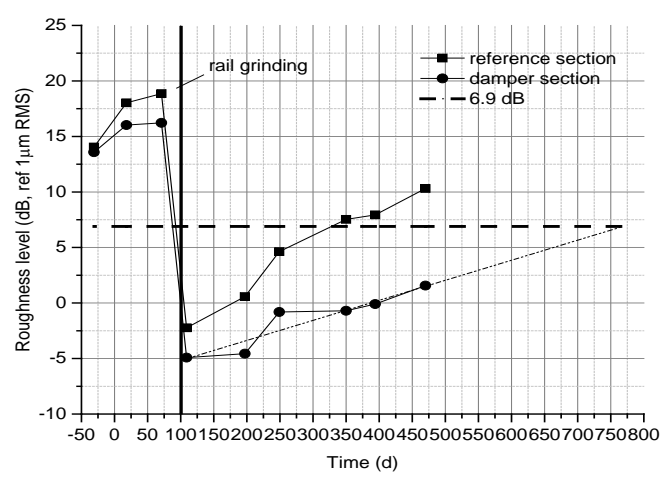

Figure 29. Development of roughness level in 63 $\mathrm{mm}$ wavelength band in reference section and damper section

\section{Conclusions}

Severe rail corrugation has been found to occur on track with Egg fasteners in the Beijing metro with dominant wavelengths in the range 63-100 mm. This induces rail vibration with dominant frequencies in the range $160-310 \mathrm{~Hz}$ for train speeds $60-70 \mathrm{~km} / \mathrm{h}$. A series of lightly damped resonances are found in this frequency range that are attributed to the fastener. This dynamic behaviour of the track structure in this frequency range appears to contribute to the formation of rail corrugation on Egg fastener track in combination with a strong anti-resonance of the wheelset in the vertical direction. Several possible solutions have been identified that involve changing the dynamic behaviour of the track structure to treat the corrugation.

Adding a rubber pad within the Egg fastener in parallel with the original resilient element changes the dynamic behaviour of original track by making the dynamic response peaks in the range $160-310 \mathrm{~Hz}$ move to higher frequencies. This is shown to lead to a reduction in the corrugation amplitude and can be applied in some sections where there is not such a high requirement for reducing the environmental vibrations.

Replacing the shear-type Egg fastener with a compression-type fastener with the same stiffness can also change the dynamic behaviour of original track through removing the dynamic response peaks at $160-310 \mathrm{~Hz}$. This is shown to control the corrugation growth to some degree. However, a fuller investigation would require monitoring after rail grinding. 
Installing rail dampers on the rail reduces the rail vibration through increasing the damping of the track, and changes the dynamic behaviour of the original track through moving the dynamic response peaks at $160-310 \mathrm{~Hz}$ towards lower frequency and reducing their amplitude significantly. This is shown to slow the development of rail corrugation by more than half and delay the necessity for rail grinding by a corresponding amount.

All three modifications to the track dynamics appear to be successful in controlling corrugation growth. However, it is not possible to make direct comparisons between their performance due to differing conditions in the experiments. Nevertheless it is clear that moving or reducing the dynamic response peaks of the Egg fastener track can control and even eliminate the corrugation growth.

Additionally, rail grinding was found to be effective in eliminating rail corrugation from some straight sections that initially had low amplitude corrugation.

\section{Acknowledgement}

The authors thank Jialiang Chen, Zongzhen Wu, Baoshun Liu, Linlin Du, Lei Meng, Liang Jiang and Heng Zhang for their experimental work on Line 10 and Line Yizhuang in the Beijing metro, and Ziquan Yan for his numerical calculations.

\section{Declaration of Conflicting Interests}

The author(s) declared no potential conflicts of interest with respect to the research, authorship, and/or publication of this article.

\section{Funding}

The author(s) disclosed receipt of the following financial support for the research, authorship, and/or publication of this article: This work is part of a research project supported by National Natural Science Foundation of China (grant no. 51378001).

\section{References}

[1] Sato Y, Matsumoto A and Knothe K. Review on rail corrugation studies. Wear 2002; 253: 130-139.

[2] Grassie SL. Rail corrugation: advances in measurement, understanding and treatment. Wear 2005; 258: 1224-1234.

[3] Oostermeijer KH. Review on short pitch rail corrugation studies. Wear 2008; 265: 1231-1237.

[4] Grassie SL and Kalousek J. Rail corrugation: characteristics, causes and treatments. Proc IMechE, Part F: J Rail Rapid Transit 1993; 207: 57-68.

[5] Grassie SL. Rail corrugation: characteristics, causes, and treatments. Proc IMechE, Part F: J Rail Rapid Transit 2009; 223: 581-596.

[6] Eadie D, Kalousek J and Chiddick K. The role of high positive friction (HPF) modifier in the control of short pitch corrugations and related phenomena. Wear 2002; 253: 185-192.

[7] Tomeoka M, Kabe N, Tanimoto M, et al. Friction control between wheel and rail by means of on board lubrication. Wear 2002; 253: 124-129. [8] Heyder R and Girsch G. Testing of $\mathrm{HSH}^{\circledR}$ rails in high-speed tracks to minimize rail damage. Wear 2005; 258: 1014-1021. 
[9] Hiensch M, Nielsen JCO and Verheijen E. Rail corrugation in The Netherlandsmeasurements and simulations. Wear 2002; 253: 140-149.

[10] Egana JI, Vinolas $\mathrm{J}$ and Seco $\mathrm{M}$. Investigation of the influence of rail pad stiffness on rail corrugation on a transit system. Wear 2006; 261: 216-224.

[11] Matsumoto A, Sata Y, Tanimoto M and Qi K. Study on the formation mechanism of rail corrugation on curved track. Vehicle Syst. Dyn. 1996; 25: 450-465.

[12] Zhang HG, Liu WN, Liu WF and Wu ZZ. Study on the cause and treatment of rail corrugation for Beijing metro. Wear 2014; 317(1-2): 120-128.

[13] Grassie SL and Edwards JW. Development of corrugation as a result of varying normal load. Wear 2008; 265: 1150-1155.

[14] European Committee for Standardization. Railway applications-Noise emission-Characterisation of the dynamic properties of track sections for pass by noise measurements. European Standard EN 15461: 2008+A1: 2010, 2010.

[15] Jones CJC, Thompson DJ and Diehl RJ. The use of decay rates to analyze the performance of railway track in rolling noise generation. $J$ Sound Vib 2006; 293: 485-495.

[16] Ryue J, Thompson DJ, White PR and Thompson DR. Investigations of propagating wave types in railway tracks at high frequencies. $J$ Sound Vib 2008; 315: 157-175.

[17] Ryue J, Thompson DJ, White PR and Thompson DR. Decay rates of propagating waves in railway tracks at high frequencies. $J$ Sound $\mathrm{Vib}$ 2009; 320: 955-976.

[18] European Committee for Standardization. Acoustics-Railway applications-Measurement of noise emitted by railbound vehicles. European Standard EN ISO 3095: 2013, 2013.

[19] Thompson DJ, Jones CJC, Waters TP and Farrington D. A tuned damping device for reducing noise from railway track. Appl Acoust 2007; 68: 43-57.

[20] Thompson DJ. A continuous damped vibration absorber to reduce broad-band wave propagation in beams. J Sound Vib 2008; 311: 824-842.

[21] Asmussen B, Stiebel D, Kitson P, et al, Reducing the noise emission by increasing the damping of the rail: results of a field test. In: Schulte-Werning B, Thompson DJ, et al (eds) Noise and Vibration Mitigation for Rail Transportation Systems, Proc of the 9th International Workshop on Railway Noise, Munich, Germany, September 2007, pp. 229-235. Springer, Heidelberg.

[22] Wu TX, On the railway track dynamics with rail vibration absorber for noise reduction. $J$ Sound Vib 2008, 309: 739-755.

[23] Maes J and Sol H. A double tuned rail damper-increased damping at the two first pinned-pinned frequencies. J Sound Vib 2003; 267: 721-737.

[24] Croft BE, Jones DJC and Thompson DJ. Modelling the effect of rail dampers on wheel-rail interaction forces and rail roughness growth rates. J Sound Vib 2009; 323: 17-32.

[25] Wu TX. Effects on short pitch rail 
corrugation growth of a rail vibration absorber/damper. Wear 2011; 271: 339-348.

[26] Wang A, Wang Z, Zhao Z, et al. Effects of track stiffness and tuned rail damper on rail roughness growth and rail vibration levels on metro system. in: Nielsen JCO, Anderson D, et al (eds), Noise and Vibration Mitigation for Rail Transportation Systems, Proc of the 11th International Workshop on Railway Noise, Uddevalla, Sweden, September 2013, pp. 667-674. Springer, Heidelberg.

[27] Wu TX and Wang YR. Modeling of wheel-track interaction with rail vibration damper and its application for suppressing short pitch rail corrugation. in: Nielsen JCO, Anderson D, et al (eds) Noise and Vibration Mitigation for Rail Transportation Systems, Proc of the 11th International Workshop on Railway Noise, Uddevalla, Sweden, September 2013, pp. 361-368. Springer, Heidelberg.

[28] http://tatasteelchina.com/upload/2012426104 23996267.pdf (accessed 15 October 2016). 